\title{
A Special Issue on Fluency Disorders
}

\begin{tabular}{|l|l|l|}
\hline H.H. & Hugo H. & Gregory \\
\hline
\end{tabular}

Chair, Fluency and Fluency Disorders Committee, IALP, Evanston, III., USA

During the last decade, committees of IALP have been encouraged to play a more prominent role in the society. Committees have planned programs at the last two Congresses that have focused on topics of contemporary interest. At the Hanover Congress, the Fluency and Fluency Disorders Committee organized a presentation and discussion on 'Attitudes in Stuttering Therapy: The Therapist and the Client.' Another innovation in IALP affairs is to have committees plan special issues of Folia Phoniatrica et Logopaedica. The Fluency and Fluency Disorders Committee is pleased to take responsibility for the first of these special issues.

In her article, Watson discusses objectives which challenge researchers and clinicians including better coop-

eration on an international scale. Lees reviews the way in which assessments of the speech of people who stutter has focused on disfiuency and speculates that measures of fluency are also important in understanding the nature of a client's speech. Furthermore, fluency measures during therapy may point to ways in which speech should be modified to make post-therapy speech more acceptable to the client. Kuhr provides an informative analysis of the movement in the 1960s toward a more programmed behavioral approach to stuttering therapy and the presently increased emphasis on working simultaneously with behavioral and cognitive-affective components.

There has not been much longitudinal research about childhood stuttering because so many problems are involved in doing such research. However, we are glad to give readers an overview of a longitudinal study in progress by Johannsen, Schulze, Rommel and Hage.

Bijleveld, Lebrun and van Dongen's report of a case of acquired stuttering following brain damage helps to clarify the nature of neurogenic stuttering and how it is similar to and different from developmental stuttering.

Finally, Preus provides a story that is exciting reading and at the same time gives a historical perspective and some added insight into stuttering.

(C)1994

S. KargerAG, Basel

1. 1021-7762/94/

0465-0213S8.00/0 